\title{
Metastasis of Ovarian Cancer to Breast: A Case Report and Review of Imaging Manifestations
}

This article was published in the following Dove Press journal:

Cancer Management and Research

Jing Wang (D)

Baohua Wang

Department of Ultrasound, The First Affiliated Hospital, Zhejiang University School of Medicine, Hangzhou, Zhejiang 310003, People's Republic of China
Correspondence: Jing Wang

Department of Ultrasound, The First Affiliated Hospital, Zhejiang University School of Medicine, \#79 Qingchun Road, Hangzhou, Zhejiang 310003, People's

Republic of China

$\mathrm{Tel} / \mathrm{Fax}+86$ 57/ 87236628

Email yanshu006@zju.edu.cn
Abstract: Metastasis of ovarian cancer to breast (MOCB) is rare, and the diagnosis is difficult due to the varied imaging manifestations. The objective of this paper is to report a special case of MOCB, review the imaging manifestations of MOCB and attempt to determine the characteristic imaging features that might be helpful in making the diagnosis and providing appropriate systemic therapy. A 40-year-old woman presented with a breast lesion six years after a diagnosis of ovarian serous cystadenocarcinoma. Ultrasound (US) and magnetic resonance imaging (MRI) examinations were performed; the final diagnosis was metastasis of ovarian serous cystadenocarcinoma to breast according to the histological examination and immunohistochemical examination after lumpectomy. Herein, we reviewed 41 cases diagnosed with MOCB, which include imaging of the metastatic breast lesion or a detailed description without imaging. In this review, we summarized that MOCB could present with calcifications (especially microcalcifications) on mammography (MM). MOCB presenting as inflammatory breast cancer usually shows swelling and skin thickening on MM and US, and increased fludeoxyglucose (FDG) uptake on positron emission tomography/ computed tomography (PET/CT). These manifestations could be helpful in differentiating malignant tumors from benign ones, but it may still be difficult to distinguish between primary and metastatic tumors. The correct diagnosis of MOCB requires a combination of the clinical history of the primary tumor, careful clinical examination, radiology and anatomic pathological evaluation.

Keywords: breast, imaging, neoplasm metastasis, ovarian neoplasms

\section{Background}

Metastasis to the breast from extramammary malignancies is rare, representing $0.5-2 \%$ of all breast cancers, ${ }^{1}$ the main tumors that produce metastases to the breast are malignant melanoma, distant sarcomas, lung cancer, ovarian cancer, renal cell cancer and thyroid cancer. ${ }^{2}$ Metastasis of ovarian cancer to breast (MOCB) represents $0.03-0.6 \%$ of all breast cancers, ${ }^{3}$ and ovarian serous cystadenocarcinoma is the most common type of ovarian tumor that can metastasize to the breast. ${ }^{4}$ Most patients with MOCB have no family history of primary breast cancer; the patients are usually detected with masses in the breast after being diagnosed with ovarian cancer, with a median interval from the primary cancer to the metastatic breast varying between 0 (simultaneous) and 16 years. ${ }^{5}$ Metastasis to the breast is the first presentation of malignancy in approximately $11-30 \%$ of all cases. ${ }^{6}$ The prognosis of MOCB is poor; survival has been reported between 13 days and 85 months, with higher survival rates reported in patients who underwent surgery. ${ }^{3,6}$ The establishment of the diagnosis of MOCB is important because different therapeutic methods need to be 
established for metastatic and primary breast cancers. ${ }^{7}$ However, it is still difficult to differentiate metastatic lesions from primary ones before surgery or needle biopsy due to differences in imaging findings. The purpose of this paper is to review the imaging of MOCB and attempt to find out the characteristic imaging features in different types of MOCB, which might be helpful in making the diagnosis and providing appropriate systemic therapy.

\section{Case Report}

A 40-year-old woman had been diagnosed with ovarian serous cystadenocarcinoma thirteen years ago and had undergone hysterectomy, bilateral salpingo-oophorectomy, omentectomy, lymphadenectomy, and additional chemotherapy for twelve cycles. The patient had no regular reexaminations and found no discomfort after the procedures. Seven years ago, the patient presented with a mass in the left breast that was localized, palpable and painless. The serum cancer antigen 125 level reached $87 \mathrm{U} / \mathrm{mL}$. The patient had no familial history of breast cancer. Ultrasound (US) (4 MHz, Mylab 90, Esaote, Genoa, Italy) findings showed an oval cystic mass measuring $8 * 6 * 7 \mathrm{~cm}^{3}$ in the upper outer quadrant of the left breast. The mass was anechoic with an uneven wall thickness (Figure 1A). Magnetic resonance imaging (MRI) (3.0 T, Signa HDx, GE, Connecticut, USA) findings showed a lobulated cystic mass measuring $7 * 6 * 6 \mathrm{~cm}^{3}$ located in the left breast. The mass showed a slightly high signal intensity on T1-weighted imaging (T1WI) (3.0 T; TR $400 \mathrm{~ms}$, TE $7 \mathrm{~ms}$, flip angle $90^{\circ}$ ), slightly high signal intensity on T2weighted imaging (T2WI) (3.0 T; TR $2800 \mathrm{ms,} \mathrm{TE} 108 \mathrm{~ms}$, flip angle $90^{\circ}$ ) and low signal intensity on short time inversion recovery (STIR) imaging (3.0T; TR $7800 \mathrm{~ms}$, TE $52 \mathrm{ms,}$ IT $175 \mathrm{~ms}$, flip angle $90^{\circ}$ ). The cystic wall and septum of the mass were unevenly thick and showed slight and localized enhancement on dynamic contrast-enhanced MRI (DCEMRI) (3.0T; TR $4 \mathrm{~ms}$, TE $2 \mathrm{~ms}$, flip angle 14, Gd-DTPA
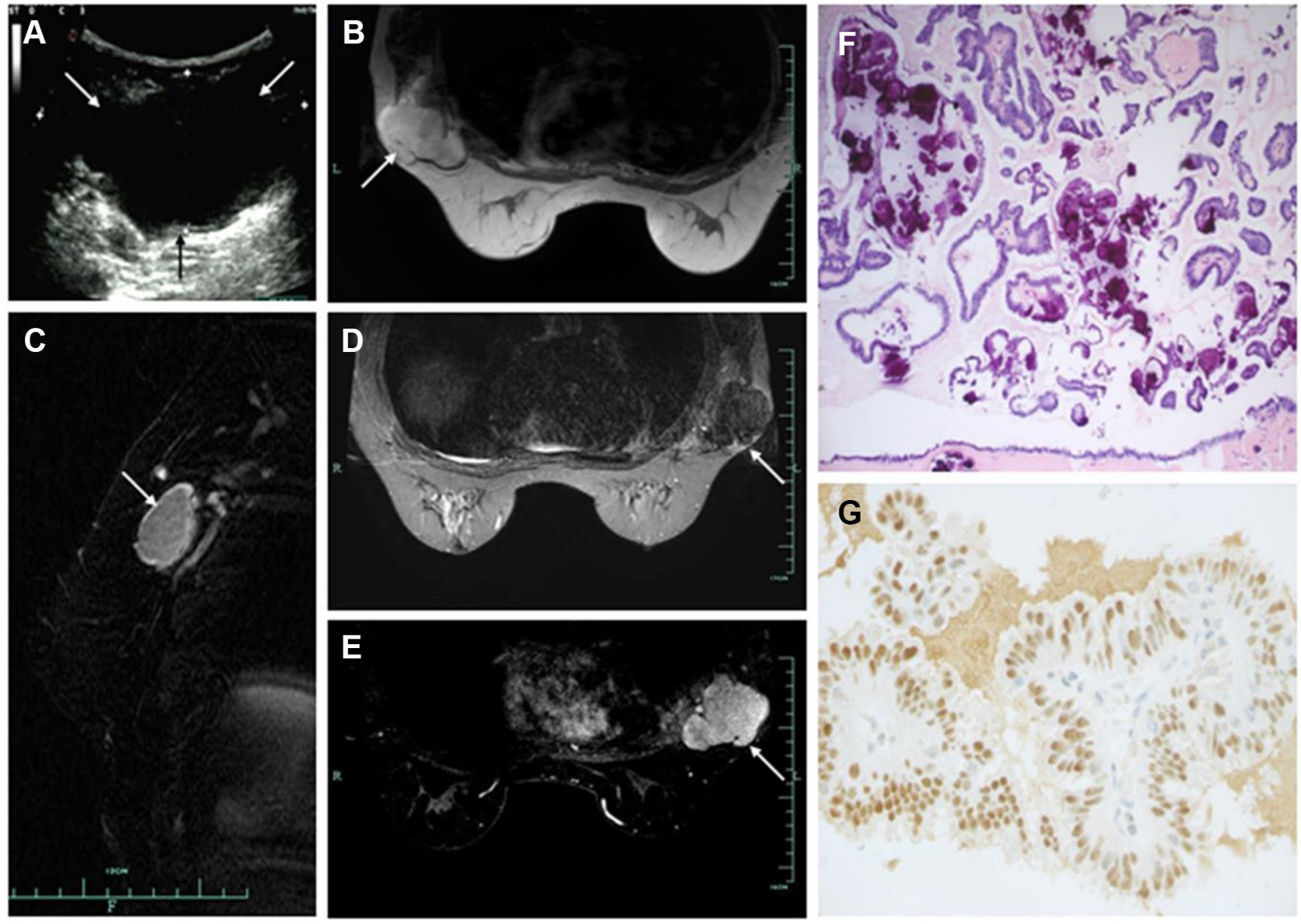

Figure I Ultrasound (A) shows an oval cystic mass with an uneven wall thickness (white and black arrows). Magnetic resonance imaging shows a lobulated cystic mass with a cystic wall and septum of uneven thickness. TI-weighted imaging (B) and T2-weighted imaging (C) show slightly high signal intensity (indicated by white arrows both in (B and C). Short time inversion recovery imaging (D) shows low signal intensity (white arrow), and dynamic contrast-enhanced magnetic resonance imaging (E) shows slight and localized enhancement on the cystic wall (white arrow). Histological examination shows an undifferentiated adenocarcinoma with cystic wall and papillary architecture (H\&E staining, $\times 100)(\mathbf{F})$. Positive immunohistochemical results for WT-I (IHC, $\times 400)(\mathbf{G})$. 
$0.1 \mathrm{mmol} / \mathrm{kg}$ ) (Figure 1B-E). Unfortunately, the patient had not undergone mammographic (MM) examination. Histological examination after lumpectomy showed an undifferentiated adenocarcinoma of unknown origin. Immunohistochemically, the tumor cells were positive for estrogen receptor (ER) and Wilms tumor 1 (WT-1) and negative for gross cystic disease fluid protein 15 (GCDFP15) (Figure $1 \mathrm{~F}-\mathrm{G}$ ). The final diagnosis was metastasis of ovarian serous cystadenocarcinoma to breast. The patient then received a combination chemotherapy of carboplatin (700 $\mathrm{mg}$ on day 1 of a 30-day cycle) and paclitaxel $\left(210 \mathrm{mg} / \mathrm{m}^{2}\right.$ on day 1 of a 30 -day cycle), which was initiated 35 days after the surgery. Unfortunately, after four chemotherapy cycles, the patient was lost to follow-up.

\section{Discussion}

Literature on MOCB is rare, and literature on radiological findings or descriptions of metastatic breast lesions is even rarer. Herein, we reviewed 41 patients (mean age, $50 \mathrm{y}$, age range, 14-82 y) diagnosed with MOCB from 1964 to 2019 , including imaging of metastatic breast lesions or detailed descriptions without imaging. The primary tumors were ovarian serous cystadenocarcinomas (OSCs) $(n=32$, $78.05 \%)$, ovarian clear-cell carcinomas (OCCCs) $(n=2$, $4.88 \%$ ), ovarian granulosa cell tumors (OGCTs) $(n=1$, $2.44 \%$ ), ovarian small-cell carcinomas (OSCCs) $(n=1$, $2.44 \%$ ) and ovarian carcinomas of unknown pathology $(\mathrm{n}=5,12.19 \%)$. Among the 41 lesions, the diameters of 17 were described with a diameter of $3.00 \mathrm{~cm}$, and the location was described for 36 , with 16, 12 and 8 lesions in the right, left, and bilateral breasts respectively. The quadrant was described for 14 , and we summarized that the common quadrant for metastases was the upper outer quadrant of the breast $(n=9,64.28 \%)$, which may be ascribed to the increase in blood supply in this region. ${ }^{8}$ We also summarized that a single lesion was more frequently identified $(n=39,95.12 \%)$. Breast metastases from extramammary malignancies have both hematogenous and lymphatic routes, and the imaging characteristics vary. Hematogenous disseminated lesions are commonly oval and circumscribed, while lymphatic dissemination may lead to diffuse breast involvement and swollen and skin thickening, which might mimic inflammatory carcinoma. $^{9,10}$ Five lesions presented as no-mass type with swelling and skin thickening, and all presented as mimic inflammatory breast cancers. It is worth mentioning that there were a total of 6 lesions presenting as inflammatory carcinoma, and 1 lesion was described as a "mass" with the primary carcinoma being OCCC.

There were 32 patients who had undergone MM examinations, and the characteristic imaging results were summarized in Table 1. According to the literature, the MM imaging of breast metastases from extramammary organs usually presented as high density, oval and circumscribed masses and generally without skin or nipple retraction. ${ }^{1,11}$ However, others demonstrated that the margins could also be microlobulated or indistinct. ${ }^{9}$ The shapes and borders of breast metastatic lesions from the ovary were oval/spiculated and circumscribed/indistinct according to the summary in this review. Calcifications were not common in breast metastases from extramammary organs, excluding MOCB, which may contain psammomatous bodies. ${ }^{9,12}$ The first report of calcification in breast metastatic lesions from OSC was as early as $1974 .{ }^{13}$ Herein, we summarized that calcification could occur in metastatic breast lesions, and microcalcification was common, accounting for $43.75 \%$ $(14 / 32)$ and $46.43 \%(13 / 28)$ of metastatic lesions from all cancer types and OSCs, respectively. Moreover, there were 2 cases of macrocalcification: one was a metastatic lesion from OSC presenting as multiple calcifications, and another was metastasis from ovarian carcinoma of unknown

Table I Characteristics of MM Imaging for Different Types of MOCB

\begin{tabular}{|c|c|c|c|c|}
\hline Characteristics & $\begin{array}{l}\text { OSC } \\
(n=28)\end{array}$ & $\begin{array}{l}\text { OCcC } \\
(n=1)\end{array}$ & $\begin{array}{l}\text { Unknown } \\
(n=3)\end{array}$ & $\begin{array}{l}\text { Total } \\
(n=32)\end{array}$ \\
\hline \multicolumn{5}{|l|}{ Shape } \\
\hline Oval & $9(9 / 16)$ & & $\mathrm{I}(\mathrm{I} / 2)$ & $10(10 / 19)$ \\
\hline Spiculated & $7(7 / 16)$ & $\mathrm{I}(\mathrm{I} / \mathrm{I})$ & $\mathrm{I}(\mathrm{I} / 2)$ & $9(10 / 19)$ \\
\hline \multicolumn{5}{|l|}{ Border } \\
\hline Circumscribed & $7(7 / 16)$ & & $I(I / 3)$ & $8(8 / 20)$ \\
\hline Indistinct & $9(9 / 16)$ & $I(I / I)$ & $2(2 / 3)$ & $12(12 / 20)$ \\
\hline \multicolumn{5}{|l|}{ Calcification } \\
\hline Microcalcification & $13(13 / 28)$ & & $I(I / 3)$ & $14(\mid 4 / 32)$ \\
\hline Macrocalcification & $I(I / 28)$ & & $\mathrm{I}(\mathrm{I} / 3)$ & $2(2 / 32)$ \\
\hline No calcification & $14(14 / 28)$ & $I(I / I)$ & $I(I / 3)$ & $16(16 / 32)$ \\
\hline \multicolumn{5}{|l|}{$\begin{array}{l}\text { Swollen and skin } \\
\text { thickening }\end{array}$} \\
\hline Yes & $2(2 / 28)$ & $I(I / I)$ & & $3(3 / 32)$ \\
\hline No & $26(26 / 28)$ & & $3(3 / 3)$ & $29(29 / 32)$ \\
\hline High density (Yes) & $26(26 / 26)$ & $\mathrm{I}(\mathrm{I} / \mathrm{I})$ & $3(3 / 3)$ & $30(30 / 30)$ \\
\hline
\end{tabular}

Notes: A total of 32 cases were summarized; the Shapes of 19 were described, the Borders of 20 were described, the Calcifications and Swollen and skin thickening of 32 were described, the Densities of 30 were described. Cases with metastatic lesions from ovarian granulosa cell tumor (OGCT) and ovarian small-cell carcinoma (OSCC) were not examined by MM.

Abbreviations: OSC, ovarian serous cystadenocarcinoma; OCCC, ovarian clearcell carcinoma; Unknown, ovarian carcinoma of unknown pathology. 
pathology presenting as a ring-shaped calcification. As a malignant sign of breast tumors, microcalcification plays a significant role in distinguishing malignant tumors from benign ones; despite its presence, however, it may still be difficult to differentiate between primary and metastatic lesions. Among the 32 lesions, the dense of 30 were described, with all presenting as high density, and the skin were described for 32, with 3 presenting as swelling and skin thickening. Patients presenting with skin thickening might suffer lymphatic route metastases, which mimic inflammatory carcinoma. In 1964, breast metastases from extramammary mimicking inflammatory carcinoma were first reported. ${ }^{14}$ Primary inflammatory breast cancer is characterized by erythema and skin thickening due to extensive lymphatic tumor emboli in the breast dermis. ${ }^{15}$ The 3 lesions presenting as inflammatory carcinoma consisted of 2 metastatic lesions from OSCs and 1 metastatic lesion from OCCC. OCCC is of the epithelial subtype, occurring in $1-25 \%$ of epithelial ovarian cancers, and $4-10 \%$ of those presenting with lymph node metastasis. ${ }^{16,17}$
The typical US features hematogenous metastases from extramammary malignancies to breast include oval shaped, circumscribed hypoechoic masses without calcifications or architectural distortion. ${ }^{18}$ In this review, only 17 patients had undergone breast US examination, and the lesions presented as solid (accounting for $70.00 \%$ and $50.00 \%$ of breast lesions metastasized from all cancer types and OSCs, respectively), hypoechoic (accounting for 57.14\% and $62.50 \%$ of breast lesions metastasized from all cancer types and OSCs), oval/spiculated and circumscribed/indistinct lesions without calcification (accounting for $94.11 \%$ and $90.00 \%$ of breast lesions metastasized from all cancer types and OSCs), which were summarized in Table 2. The different presentations of calcification in metastatic breast lesions of the ovary on MM and US imaging may be ascribed to the low diagnostic rate of calcification on US. Swelling and skin thickening $(n=3,17.70 \%)$ were also not common. All of these were metastases mimicking inflammatory breast carcinoma, which contained features similar to those seen on MM. Hyperechoic lesions were unusual,

Table 2 Characteristics of US Imaging for Different Types of MOCB

\begin{tabular}{|c|c|c|c|c|c|c|}
\hline Characteristics & $\operatorname{OSC}(n=10)$ & $\operatorname{OCCC}(n=1)$ & OGCT $(n=1)$ & $\operatorname{Oscc}(n=1)$ & Unknown $(n=4)$ & Total $(n=\mid 7)$ \\
\hline \multicolumn{7}{|l|}{ Shape } \\
\hline Oval & $2(2 / 3)$ & & $\mathrm{I}(\mathrm{I} / \mathrm{I})$ & $\mathrm{I}(\mathrm{I} / \mathrm{I})$ & $2(2 / 4)$ & $6(6 / 10)$ \\
\hline Spiculated & $\mathrm{I}(\mathrm{I} / 3)$ & $\mathrm{I}(\mathrm{I} / \mathrm{I})$ & & & $2(2 / 4)$ & $4(4 / 10)$ \\
\hline \multicolumn{7}{|l|}{ Border } \\
\hline Circumscribed & $\mathrm{I}(\mathrm{I} / 3)$ & & $\mathrm{I}(\mathrm{I} / \mathrm{I})$ & $\mathrm{I}(\mathrm{I} / \mathrm{I})$ & $2(2 / 4)$ & $5(5 / 10)$ \\
\hline Indistinct & $2(2 / 3)$ & $\mathrm{I}(\mathrm{I} / \mathrm{I})$ & & & $2(2 / 4)$ & $5(5 / 10)$ \\
\hline \multicolumn{7}{|l|}{ Calcification } \\
\hline Microcalcification & $\mathrm{I}(\mathrm{I} / \mathrm{I0})$ & & & & & $\mathrm{I}(\mathrm{I} / \mathrm{I7})$ \\
\hline No calcification & $9(9 / 10)$ & $\mathrm{I}(\mathrm{I} / \mathrm{I})$ & $\mathrm{I}(\mathrm{I} / \mathrm{I})$ & $\mathrm{I}(\mathrm{I} / \mathrm{I})$ & $4(4 / 4)$ & $16(16 / 17)$ \\
\hline \multicolumn{7}{|l|}{ Swollen and skin thickening } \\
\hline Yes & $2(2 / 10)$ & $\mathrm{I}(\mathrm{I} / \mathrm{I})$ & & & & $3(3 / 17)$ \\
\hline No & $8(8 / 10)$ & & $\mathrm{I}(\mathrm{I} / \mathrm{I})$ & $\mathrm{I}(\mathrm{I} / \mathrm{I})$ & $4(4 / 4)$ & $14(14 / 17)$ \\
\hline \multicolumn{7}{|l|}{ Echogenicity } \\
\hline Hypoechoic & $5(5 / 8)$ & & $\mathrm{I}(\mathrm{I} / \mathrm{I})$ & & $2(2 / 3)$ & $8(8 / 14)$ \\
\hline Hyperechoic & & & & $\mathrm{I}(\mathrm{I} / \mathrm{I})$ & & $I(I / / 4)$ \\
\hline Anechoic & $\mathrm{I}(\mathrm{I} / 8)$ & & & & & $I(1 / 14)$ \\
\hline Mixed & $2(2 / 8)$ & $\mathrm{I}(\mathrm{I} / \mathrm{I})$ & & & $\mathrm{I}(\mathrm{I} / 3)$ & $4(4 / 14)$ \\
\hline \multicolumn{7}{|l|}{ Component } \\
\hline Solid & $2(2 / 4)$ & $\mathrm{I}(\mathrm{I} / \mathrm{I})$ & $\mathrm{I}(\mathrm{I} / \mathrm{I})$ & $\mathrm{I}(\mathrm{I} / \mathrm{I})$ & $2(2 / 3)$ & $7(7 / 10)$ \\
\hline Cystic and solid & $\mathrm{I}(\mathrm{I} / 4)$ & & & & $\mathrm{I}(\mathrm{I} / 3)$ & $2(2 / 10)$ \\
\hline Cystic & $\mathrm{I}(\mathrm{I} / 4)$ & & & & & $I(I / I 0)$ \\
\hline
\end{tabular}

Notes: A total of 17 cases were summarized; the Shapes and Borders of 10 were described, the Calcifications and Swollen and skin thickening of 17 were described, the Echogenicity of 14 were described, the Components of 10 were described.

Abbreviations: OSC, ovarian serous cystadenocarcinoma; OCCC, ovarian clear-cell carcinoma; OGCT, ovarian granulosa cell tumor; OSCC, ovarian small-cell carcinoma; Unknown, ovarian carcinoma of unknown pathology. 
only appearing in the metastatic breast of OSCC in our review. OSCC is a rare, highly malignant tumor that usually affects young women. ${ }^{19}$ The sole case in this review reported on a 14-year-old girl suffering this disease; the metastases showed multiple, round, well-defined hyperechoic and hypoechoic masses in the bilateral breasts. Intratumoral cystic components were also not common, as there were few reports describing this. Most of these were in patients with synovial sarcoma from the thigh or hepatocellular carcinoma and insular carcinoma of the thyroid gland. ${ }^{18}$ Herein, we summarized 3 lesions ( 2 metastasized from OSCs and 1 metastasized from ovarian carcinoma of unknown pathology) containing cystic components in this review. Interestingly, the US imaging of our case report revealed an oval cystic mass. In addition, we reviewed 1 patient with metastasis from OGCT who underwent US examination only. OGCT is a rare neoplasm arising from sex-cord-stromal cells and is frequently associated with hormonal cancer, and only a small percentage of this type of ovarian carcinoma exhibits metastasis. ${ }^{20}$ This case presented as oval-shaped, circumscribed, hypoechoic masses without calcifications or skin thickening. Unfortunately, the number of patients who underwent US imaging in this review was small, and the characteristic imaging manifestations could not be well summarized here.
In this review, 5 metastatic lesions of OSCs were examined by positron emission tomography/computed tomography (PET/CT). Three of those presented with inflammatory breast cancer with increased fludeoxyglucose (FDG) uptake and skin thickening, and the other 2 masses also had increased FDG uptake (Table 3). PET/CT is not typically used in the diagnosis of MOCB, and metastatic lesions are often found accidentally. PET/CT can detect smaller tumors with increased FDG uptake, ${ }^{21}$ however, it is unable to play a major role in distinguishing primary and metastatic breast tumors because of the similar imaging characteristics. ${ }^{22}$

MRI is also rarely used in the diagnosis of breast metastatic lesions. The imaging on MRI might present as an oval mass with intermediate signal on T2WI and low signal on T1WI as well as fast and homogeneous enhancement. ${ }^{12}$ Herein, only 3 lesions ( 2 lesions metastasized from OSCs and 1 lesion metastasized from ovarian carcinoma of unknown pathology) had MRI imaging or descriptions in this review, and all presented with homogenous/inhomogeneous enhancement (Table 3). In our case report, the patient had undergone MRI examination. The imaging showed a lobulated cystic mass with a cystic wall and septum of uneven thickness, slightly high signal intensity on T1WI and T2 WI, low signal intensity on STIR, and slight enhancement in the cystic wall and septum on DCE-MRI.

Table 3 Characteristics of PET/CT, MRI, and CT Imaging for Different Types of MOCB

\begin{tabular}{|c|c|c|c|c|c|}
\hline Characteristics & OSC & OCCC & oscc & Unknown & Total \\
\hline \multicolumn{6}{|l|}{$\mathrm{PET} / \mathrm{CT}(\mathrm{n}=5)$} \\
\hline FDG uptake increasing (Yes) & $5(5 / 5)$ & & & & $5(5 / 5)$ \\
\hline \multicolumn{6}{|l|}{ Swollen and skin thickening } \\
\hline Yes & $3(3 / 5)$ & & & & $3(3 / 5)$ \\
\hline No & $2(2 / 5)$ & & & & $2(2 / 5)$ \\
\hline \multicolumn{6}{|l|}{$M R I(n=3)$} \\
\hline \multicolumn{6}{|l|}{ Enhancement } \\
\hline Homogenous & $\mathrm{I}(\mathrm{I} / 2)$ & & & & $I(I / 3)$ \\
\hline Inhomogenous & $\mathrm{I}(\mathrm{I} / 2)$ & & & $\mathrm{I}(\mathrm{I} / \mathrm{I})$ & $2(2 / 3)$ \\
\hline \multicolumn{6}{|l|}{$C T(n=2)$} \\
\hline \multicolumn{6}{|l|}{ Shape } \\
\hline Oval & & & $\mathrm{I}(\mathrm{I} / \mathrm{I})$ & & $\mathrm{I}(\mathrm{I} / 2)$ \\
\hline Spiculated & & $\mathrm{I}(\mathrm{I} / \mathrm{I})$ & & & $I(I / 2)$ \\
\hline \multicolumn{6}{|l|}{ Border } \\
\hline Circumscribed & & & $\mathrm{I}(\mathrm{I} / \mathrm{I})$ & & $I(I / 2)$ \\
\hline Indistinct & & $\mathrm{I}(\mathrm{I} / \mathrm{I})$ & & & $\mathrm{I}(\mathrm{I} / 2)$ \\
\hline High density (Yes) & & $\mathrm{I}(\mathrm{I} / \mathrm{I})$ & $\mathrm{I}(\mathrm{I} / \mathrm{I})$ & & $2(2 / 2)$ \\
\hline
\end{tabular}

Notes: Five cases were examined by PET/CT. Three cases were examined by MRI. Two cases were examined by CT.

Abbreviations: OSC, ovarian serous cystadenocarcinoma; OCCC, ovarian clear-cell carcinoma; OSCC, ovarian small-cell carcinoma; Unknown, ovarian carcinoma of unknown pathology. 
Only 2 patients (metastasis from OSCC and OCCC) underwent computed tomography (CT) imaging in this review. The patient with metastatic lesions from OSCC presented with multiple high-density, oval, circumscribed masses, while the patient with metastatic breast lesions from OCCC presented with a high-density, spiculated, indistinct mass (Table 3).

\section{Conclusions}

As a matter of fact, the number of cases is small in this review so that we can only make a simple description and summary of the imaging characteristics rather than carry out effective statistics. Herein, we summarized that MOCB (especially that metastasized from OSCs) could present with calcifications (especially microcalcifications) on MM. MOCB presenting as an inflammatory breast cancer usually showed swelling and skin thickening on $\mathrm{MM}$ and US and increased FDG uptake on PET/CT. We hold the opinion that these manifestations could be helpful in differentiating malignant tumors from benign ones, but it may still be difficult to distinguish between primary and metastatic tumors. The correct diagnosis of MOCB requires a combination of clinical history of the primary tumor, careful clinical examination, radiology and anatomic pathological evaluation.

MOCB has a low incidence and a high misdiagnosis rate. However, it cannot be ignored for the different management of primary and metastatic tumors. We need to pay attention to the finding of a new breast lesion in patient diagnosed with ovarian cancer for it may be MOCB. Though there is no characteristic imaging manifestations in different types of MOCB, which has been summarized in this review, we still hope to find out the special imaging manifestations after collecting and reviewing more cases of MOCB in the future. What's more, we hope to provide more accurate and reliable information to the surgeons and the patients before surgery or needle biopsy.

\section{Informed Consent and Ethical Statements}

Informed consent for publication of the case details and accompanying images has been obtained from the patient's next of kin. Ethical approval for this investigation was obtained from Clinical Research Ethics Committee of the First Affiliated Hospital, College of Medicine, Zhejiang University.

\section{Disclosure}

The authors report no conflicts of interest in this work.

\section{References}

1. Pesce K, Chico MJ, Delgado JS, Sierra ACZ, Hadad C, Wernicke A. Metástasis en la mama, un diagnóstico infrecuente. ¿Qué deben saber los radiólogos? Radiología. 2019;61(4):324-332. doi:10.1016/j.rx.20 19.02.004

2. Wienbeck S, Nemat S, Lotz J, Surov A. Imaging diagnostics of breast metastases from extramammary tumors. Der Radiologe. 2017;57 (6):459-465. doi:10.1007/s00117-017-0247-6

3. Recine MA, Deavers MT, Middleton LP, Silva EG, Malpica A. Serous carcinoma of the ovary and peritoneum with metastases to the breast and axillary lymph nodes: a potential pitfall. Am J Surg Pathol. 2004;28(12):1646-1651. doi:10.1097/00000478-20041200000015

4. Antuono L, Angela F, Luca N, Giovanni M, Enrico C. Breast metastasis from ovarian cancer: A case report. Radiol Case Rep. 2018;13 (6):1166-1169. doi:10.1016/j.radcr.2018.08.008

5. DeLair DF, Corben AD, Catalano JP, Vallejo CE, Brogi E, Tan LK. Non-mammary metastases to the breast and axilla: a study of 85 cases. Mod Pathol. 2013;26(3):343-349. doi:10.1038/modpathol.20 12.191

6. Williams SA, Ehlers RA, Hunt K, et al. Metastases to the breast from nonbreast solid neoplasms: presentation and determinants of survival. Cancer. 2007;110(4):731-737. doi:10.1002/cncr.22835

7. Tempfer CB, El Fizazi N, Ergonenc H, Solass W. Metastasis of ovarian cancer to the breast: A report of two cases and a review of the literature. Oncol Lett. 2016;11(6):4008-4012. doi:10.3892/ol.20 16.4514

8. Lee SH, Park JM, Kook SH, Han BK, Moon WK. Metastatic tumors to the breast: mammographic and ultrasonographic findings.. $J$ Ultrasound Med. 2000;19(4):257-262. doi:10.7863/jum.2000.19. 4.257

9. Sippo DA, Kulkarni K, Carlo PD, et al. Metastatic Disease to the Breast From Extramammary Malignancies: A Multimodality Pictorial Review. Current Problems in Diagnostic Radiology. 2016;45 (3):225-232. doi:10.1067/j.cpradiol.2015.07.001

10. Surov A, Fiedler E, Holzhausen H-J, Ruschke K, Schmoll H-J, Spielmann R-P. Metastases to the breast from non-mammary malignancies: primary tumors, prevalence, clinical signs, and radiological features. Acad Radiol. 2011;18(5):565-574. doi:10.1016/j.acra.20 10.12.009

11. Abbas J, Wienke A, Spielmann RP, Bach AG, Surov A. Intramammary metastases: comparison of mammographic and ultrasound features. Eur J Radiol. 2013;82(9):1423-1430. doi:10.1016/j. ejrad.2013.04.032

12. Bitencourt AGV, Gama RRM, Graziano L, et al. Breast metastases from extramammary malignancies: multimodality imaging aspects. Br J Radiol. 2017;90(1077):20170197. doi:10.1259/bjr.20170197

13. Moncada R, Cooper RA, Garces M, Badrinath K. Calcified metastases from malignant ovarian neoplasm. Review of the literature. Radiology. 1974;113(1):31-35. doi:10.1148/113.1.31

14. Ibach JR. Carcinoma of the ovary metastatic to breast. A case report and review of the literature. Arch Surg. 1964;88(3):410-414. doi:10.1001/archsurg.1964.01310210084013

15. Sato T, Muto I, Fushiki M, et al. Metastatic breast cancer from gastric and ovarian cancer, mimicking inflammatory breast cancer: report of two cases. Breast Cancer. 2008;15(4):315-320. doi:10.1007/s12282008-0040-5

16. Chan JK, Cheung MK, Husain A, et al. Patterns and progress in ovarian cancer over 14 years. Obstet Gynecol. 2006;108(3, Part 1):521-528. doi:10.1097/01.AOG.0000231680.58221.a7 
17. Yamazaki H, Todo Y, Shimada C, et al. Therapeutic significance of full lymphadenectomy in early-stage ovarian clear cell carcinoma. J Gynecol Oncol. 2018;29(2):e19. doi:10.3802/jgo.2018.29.e19

18. Mun SH, Ko EY, Han B-K, Shin JH, Kim SJ, Cho EY. Breast metastases from extramammary malignancies: typical and atypical ultrasound features. Korean J Radiol. 2014;15(1):20-28. doi:10. 3348/kjr.2014.15.1.20

19. Cheng Z, Yin H, Du J, Yue X, Qian X, Liu B. Bilateral breast metastasis from small-cell carcinoma of the ovary. J Clin Oncol. 2008;26(31):5129-5130. doi:10.1200/JCO.2008.16.4640

20. Chauhan A, Dahiya P, Singh H, Gill M, Verma S. Isolated breast metastasis from granulosa cell tumor of the ovary. Arch Gynecol Obstet. 2009;280(6):997-999. doi:10.1007/s00404-009-1025-0
21. Chung A, Schoder H, Sampson M, Morrow M, Port E. Incidental breast lesions identified by $18 \mathrm{~F}$-fluorodeoxyglucose-positron emission tomography. Ann Surg Oncol. 2010;17(8):2119-2125. doi:10.12 45/s10434-010-0950-2

22. Benveniste AP, Marom EM, Benveniste MF, Mawlawi OR, Miranda RN, Yang W. Metastases to the breast from extramammary malignancies - PET/CT findings. Eur $J$ Radiol. 2014;83(7): 1106-1112. doi:10.1016/j.ejrad.2014.04.015

\section{Publish your work in this journal}

Cancer Management and Research is an international, peer-reviewed open access journal focusing on cancer research and the optimal use of preventative and integrated treatment interventions to achieve improved outcomes, enhanced survival and quality of life for the cancer patient.
The manuscript management system is completely online and includes a very quick and fair peer-review system, which is all easy to use. Visit http://www.dovepress.com/testimonials.php to read real quotes from published authors. 